\title{
Vein of Galen Malformations: Case Report \& Review
}

\author{
Snigdha Goyal ${ }^{*}$, Sunder Goyal ${ }^{2}$, Isha Saini², Sarita Bishnoi ${ }^{3}$ \\ ${ }^{1}$ Department of Pathology, Dr. RML Postgraduate Institute of Medical Sciences \& Research, New Delhi, India \\ ${ }^{2}$ Department of Surgery, Kalpana Chawla Government Medical College, Karnal, India \\ ${ }^{3}$ Department of Radiology, Kalpana Chawla Government Medical College, Karnal, India \\ Email: ${ }^{*}$ goyal.sunder@yahoo.in
}

Received 1 July 2015; accepted 18 July 2015; published 23 July 2015

Copyright (C) 2015 by authors and OALib.

This work is licensed under the Creative Commons Attribution International License (CC BY).

http://creativecommons.org/licenses/by/4.0/

(c) (i) Open Access

\begin{abstract}
Vein of Galen aneurysmal malformations (VGAMs) are rare congenital abnormalities that can cause severe morbidity and mortality. VGAMs present in different way from vein of Galen aneurysmal dilatations (VGADs). The VGAMS have a parenchymal arteriovenous malformation that drains through the vein of Galen whereas VGADs may present with intracranial hemorrhage. In neonates VGAMs result in high-output cardiac failure. Surgery offers little improvement, with fatal outcomes in $80 \%$ to $100 \%$ of cases.
\end{abstract}

\section{Keywords}

Vein of Galen Aneurysmal Malformation, Vein of Galen Aneurysmal Dilatation

Subject Areas: Clinical Trials, Public Health

\section{Introduction}

Vein of Galen aneurysmal malformations (VGAMs) and vein of Galen aneurysmal dilations (VGADs), are the most common arteriovenous malformations in infants and fetuses [1]. VGAM consisted of a jumbled mass of dilated vessels supplied by an enlarged artery [2]. The malformation increases greatly in size with age without any clear mechanism [2]. Dilation of the great cerebral vein of Galen is a secondary result of the force of arterial blood either directly from an artery via an arteriovenous fistula or by way of a tributary vein that receives the blood directly from an artery [1] [2]. There is usually a venous anomaly downstream from the draining vein that, together with the high blood flow into the great cerebral vein of Galen causes its dilation [3]. The right side cardiac chambers and pulmonary arteries also develop mild to severe dilation [4]. Mortality rate is about $80 \%$ to $100 \%$ of cases and open surgery offers little improvement [5]. Recently, endovascular management may im-

"Corresponding author.

How to cite this paper: Goyal, S., Goyal, S., Saini, I. and Bishnoi, S. (2015) Vein of Galen Malformations: Case Report \& Review. Open Access Library Journal, 2: e1478. http://dx.doi.org/10.4236/oalib.1101478 
prove results in infants and children. However, mortality ranges from $23 \%$ to $75 \%$ and morbidity from $21 \%$ to $88 \%$ in neonates [5]. We report a case of vein of Galen malformation in child of 2 years age.

\section{Case Report}

A 2 years old boy presented to the pediatrics outpatient department with a complaint of enlargement of head size. There was history delayed mile stones and also of seizure once. General and cardiovascular examinations, as well as routine biochemical analysis were within normal limits. There was no evidence of skin lesions to suggest capillary malformation neither there was any limb hypertrophy. There was no family history of skin lesions, limb hypertrophy or vascular malformations. Skull ultrasound (USG) done outside reported a heterogeneous, predominantly hypoechoic lesion in region posterior to third ventricle with dilated lateral and third ventricle and normal-sized fourth ventricle suggestive of obstructive hydrocephalus. Slow flow was also detected within the lesion. Computerized tomography skull done confirmed the findings of USG, and showed heterogeneous intensity lesion in the pineal region causing mass effect on aqueduct. CECT angiography and venography were also performed which well delineated the lesion (Figure 1). Patient was advised endovascular embolization. Patient lost the follow up.

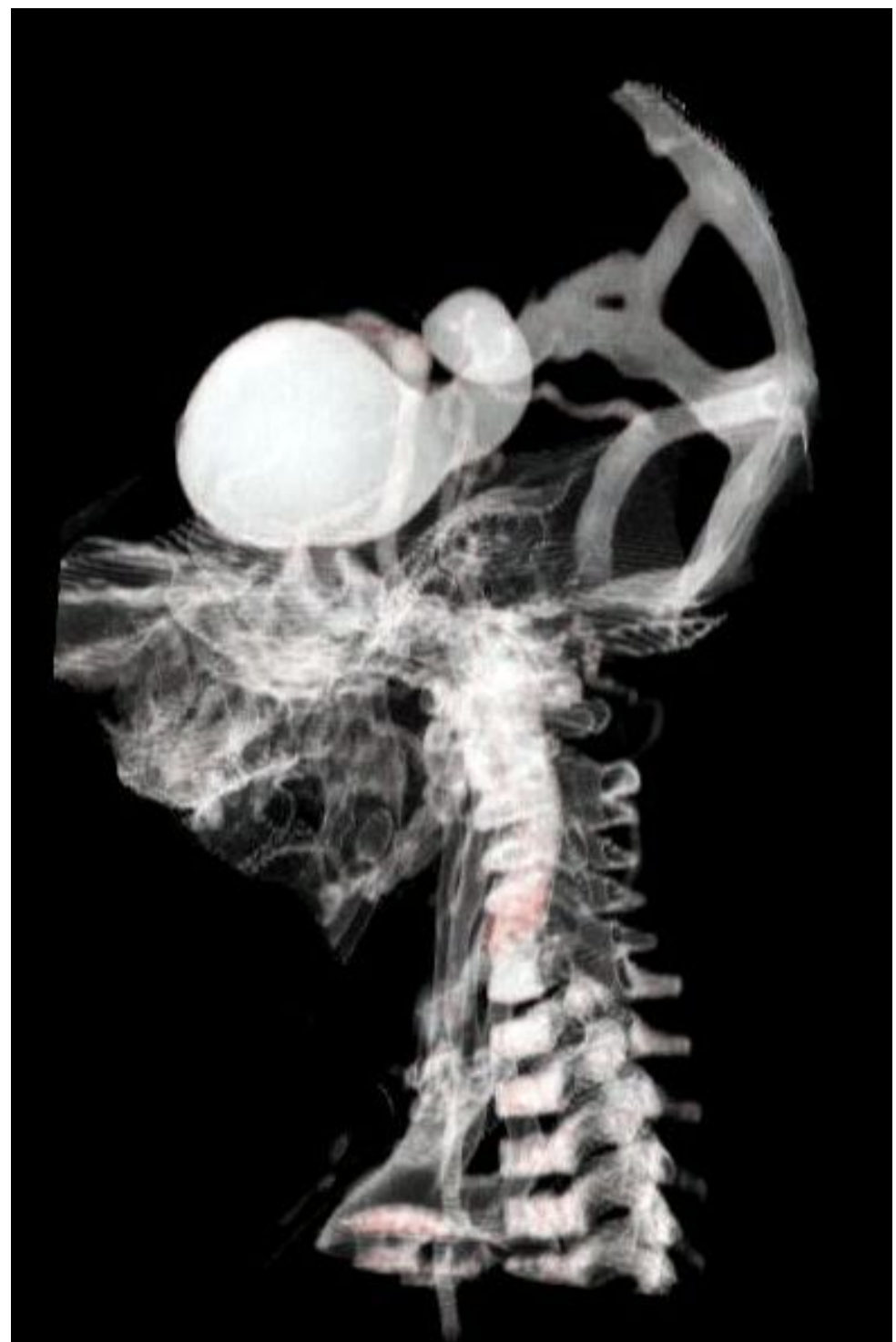

Figure 1. CECT showing vein of Galen malformation. 


\section{Discussion}

The vein of Galen (great cerebral vein or great vein of Galen) is a short vascular trunk formed by the union of the two internal cerebral veins and the basal veins of Rosenthal. Vein of Galen aneurysmal malformation (VGAM) occurs during 6 - 11 weeks of fetal life due to teratogenic effect. Aneurysmal dilatation of vein of Galen and arteriovenous shunting of blood occurs due to persistence of embryonic pros encephalic vein of Markowski. VGAM can be associated with capillary malformation-arteriovenous malformation (CM-AVM). It is an autosomal dominant disorder due to mutation in RASA1 gene [6].

Several proposed classification systems have been used to describe malformations of the vein of Galen. Five patterns of Galenic arteriovenous malformations have been described:

Pattern 1-Many vessels, including anterior cerebral arteries, thalamic perforating arteries, and superior cerebellar arteries discharge into the vein of Galen [7].

Pattern 2-A single posterior choroidal artery drains into the vein of Galen [7].

Pattern 3-One or both posterior choroidal and one or both anterior cerebral arteries drain directly into the Galenic system [7].

Pattern 4-An angiomatous network of posterior choroidal and thalamic perforating arteries enters the vein of Galen directly [7].

Pattern 5-A high flow arteriovenous malformation in the right inferior frontal lobe drains via the inferior sagittal sinus and pericallosal vein into the Vein of Galen [3].

Small arteriovenous shunts causes progressive neurological impairment where as larger arteriovenous shunts are linked with greater hemodynamic effects and thus result in earlier symptom [8].

Malformations frequently cause cardiac failure, cranial bruits (pattern 1), hydrocephaly, and subarachnoid hemorrhage in neonates. The heart failure is due to the size of the arteriovenous shunt that can steal $80 \%$ or more of the cardiac output, with large volumes of blood under high pressure returning to the right heart and pulmonary circulation and sinus venosus atrialseptal defects [3] [4]. It is the most common cause of death in such patients [9].

There can be extremely rare non-developmental syndromes like superior vena cava syndrome (SVCS), and thrombosis of the lateral sinus, superior sagittal sinus, internal jugular vein, or of the Great Cerebral Vein of Galen itself.

In a child with unexplained heart failure, malformed vein of Galen should be suspected. On examination there can be dilated facial veins along with cranial bruits. Ultrasound, Doppler, Computerized tomography (CECT) and magnetic imaging resonance (MRI) are useful radiological diagnostic tools for vein of Galen malformations [3]. To improve outcomes in survivors, transcranial sonography and fetal MR imaging can help in antenatal diagnosis [10]-[12]. Many cases are diagnosed only during autopsy as congestive heart failure occurs very early [7].

VGAM should be differentiated from arachnoid cyst, cavum vergae and porencephalic cyst. There is no evidence of intralesional flow in these lesions.

Color-flow imaging and pulsed Doppler ultrasonography are noninvasive tools to assess anatomical and pathophysiological information about cardiac hemodynamics and intracranial blood flow [13].

Treatment depends on the structure of the malformation [3]. A ventriculoperitoneal shunt may be required if there is hydrocephalous. To reduce the blood flow into the vein, the feeding fistulous arteries into the Vein of Galen must be blocked [7].

As structure of malformation is complicated, so, open surgery is very difficult. Mostly endovascular procedures are very useful [14]. In the highest-risk neonates with VGAMs and cardiac failure, endovascular therapy can reduce the mortality nearly $100 \%$ [15]. With the help of catheters drugs, balloons, or coils can be delivered at the site of the malformation to stop blood flow through the vein [14]. During catheterization of vein, guide wire can damage the wall of the vein can be damaged and, in some cases, may dislodge the emboli [4]. Endovascular procedures offer safe, successful treatment if cardiac failure cannot be controlled with medical therapy [15].

Another treatment option is radio surgery in which blood vessel is damaged with the help of focused beam but it is very slow process and may takes months to years [16]. Seizures usually are managed with antiepileptic medications [16].

Most noted complication is intracranial hemorrhages [17]. In about half of the patients malformations are untreatable and these patients mostly die in the neonatal period or in early infancy [4]. Incidence of mortality is about $77 \%$ in untreated cases [18]. The mortality rate is about $39.4 \%$ even after surgery [18]. 


\section{Conclusion}

Vein of Galen malformations are rare malformations. Clinicians should be given awareness about this condition for proper management and for better prognosis. With proper selection of cases, good results can be acquired.

\section{References}

[1] O’Brien, M. and Schechter, M. (1970) Arteriovenous Malformations Involving the Galenic System. The American Journal of Roentgenology, Radium Therapy, and Nuclear Medicine, 110, 50-55. http://dx.doi.org/10.2214/ajr.110.1.50

[2] Takashima, S. and Becker, L.E. (1980) Neuropathology of Cerebral Arteriovenous Malformations in Children. Journal of Neurology, Neurosurgery, and Psychiatry, 43, 380-385. http://dx.doi.org/10.1136/jnnp.43.5.380

[3] Nicholson, A.A., Hourihan, M.D. and Hayward, C. (1989) Arteriovenous Malformations Involving the Vein of Galen. Archives of Disease in Childhood, 64, 1653-1655. http://dx.doi.org/10.1136/adc.64.12.1653

[4] McElhinney, D.B., Halbach, V.V., Silverman, N.H., Dowd, C.F. and Hanley, F.L. (1998) Congenital Cardiac Anomalies with Vein of Galen Malformations in Infants. Archives of Disease in Childhood. Fetal and Neonatal Edition, 78, 548-551. http://dx.doi.org/10.1136/adc.78.6.548

[5] Lasjaunias, P., Rodesch, G., Terbrugge, K., et al. (1989) Vein of Galen Aneurysmal Malformations. Report of 36 Cases Managed between 1982 and 1988. Acta Neurochirurgica, 99, 26-37. http://dx.doi.org/10.1007/BF01407773

[6] Ahmad, M., Shuaib Mir, S., Wahab, S. and Rizvi, I. (2012) Vein of Galen Malformation. BMJ Case Reports. http://dx.doi.org/10.1136/bcr-2012-006822

[7] Hoffman, H.J., Chuang, S., Hendrick, E.B. and Humphreys, R.P. (1982) Aneurysms of the Vein of Galen. Experience at the Hospital for Sick Children, Toronto. Journal of Neurosurgery, 57, 316-322. http://dx.doi.org/10.3171/jns.1982.57.3.0316

[8] Padget, D.H. (1956) The Cranial Venous System in Man in Reference to Development, Adult Configuration, and Relation to the Arteries. The American Journal of Anatomy, 98, 307-355. http://dx.doi.org/10.1002/aja.1000980302

[9] Johnston, I.H., Whittle, I.R., Besser, M. and Morgan, M.K. (1987) Vein of Galen Malformation: Diagnosis and Management. Neurosurgery, 20, 747-758. http://dx.doi.org/10.1227/00006123-198705000-00013

[10] Yamashita, Y., Abe, T., Ohara, N., et al. (1992) Successful Treatment of Neonatal Aneurysmal Dilatation of the Vein of Galen: The Role of Prenatal Diagnosis and Trans-Arterial Embolization. Neuroradiology, 34, 457-459. http://dx.doi.org/10.1007/BF00596519

[11] Campi, A., Scotti, G., Filippi, M., Gerevini, S., Strigimi, F. and Lasjaunias, P. (1996) Antenatal Diagnosis of Vein of Galen Aneurysmal Malformation: MR Study of Fetal Brain and Postnatal Follow-Up. Neuroradiology, 38, 87-90. http://dx.doi.org/10.1007/BF00593231

[12] Goelz, R., Mielke, G., Gonser, M., et al. (1996) Vein of Galen Malformation: Prenatal Diagnosis and Noninvasive Procedure. Zeitschrift für Geburtshilfe und Neonatologie, 200, 72-75.

[13] Ciricillo, S.F., Schmidt, K.G., Silverman, N.H., Hieshima, G.B., Higashida, R.T., Halbach, V.V., et al. (1990) Serial Ultrasonographic Evaluation of Neonatal Vein of Galen Malformations to Assess the Efficacy of Interventional Neuroradiological Procedures. Neurosurgery (Baltimore), 27, 544-548. http://dx.doi.org/10.1227/00006123-199010000-00007

[14] The Arteriovenous Malformation Study Group (1999) Arteriovenous Malformations of the Brain in Adults. New England Journal of Medicine, 340, 1812-1818. http://dx.doi.org/10.1056/NEJM199906103402307

[15] Mitchella, P.J., Rosenfelda, J.V., Dargavillea, P., Loughnana, P., Ditchfielda, M.R., Frawleya, G., et al. (2001) Endovascular Management of Vein of Galen Aneurysmal Malformations Presenting in the Neonatal Period. AJNR, 22, 1403-1409.

[16] Chatterjee, S. (2009) Antiepileptic Drugs. Molecules of the Millennium. Indian Journal of Pharmacology.

[17] Meyers, P.M., Halbach, V.V., Phatouros, C.P., Dowd, C.F., Malek, A.M., Lempert, T.E., et al. (2000) Hemorrhagic Complications in Vein of Galen Malformations. Annals of Neurology, 47, 748-755. http://dx.doi.org/10.1002/1531-8249(200006)47:6<748::AID-ANA7>3.0.CO;2-7

[18] Alexander, M.J. and Spetzler, R.F. (2005) Pediatric Neurovascular Disease: Surgical, Endovascular, and Medical Management. Thieme Medical Publishers, New York. 